\title{
Derekutuğun Tarihöncesi Madenci Çıraları
}

\section{The Prehistoric Mining Kindlings from Derekutugun \\ Ünsal YALÇIN*}

\section{Hatice Gönül YALÇIN**}

*Deutsches Bergbau-Museum Bochum / Ruhr-Universität Bochum, uensal.yalcin@bergbaumuseum.de

**Deutsches Bergbau-Museum Bochum / Ruhr-Universität Bochum, goenuel.yalcin@bergbaumuseum.de

ORCID Numaraları | ORCID Numbers: *0000 $000186261065 / * * 0000-0002-4559-7790$

Öz: Derekutuğun Tarihöncesi Maden İșletmeleri'nde 2009-2011 ve 2015-2017 yıllarında yapılan arkeolojik kazı çalıșmaları Anadolu Madenciliği hakkında önemli bilgiler vermiş̧tir. Miyosen yaşlı sedimanların çatlak ve boşluklarında oluşan nabit bakır MÖ 3. binyılda galeriler açılarak işlenmiștir. Galerilerde ele geçen küęük buluntular arasında yeraltı galeri ve maden alma boşluklarını aydınlatmak amacıla kullanılan çıralar dikkati çekmektedir. Bölgenin yerli çam ağaçlarından elde edilen çıralar Yakın Doğu'nun kendi türünde en önemli malzeme grubunu oluștururlar.

Anahtar Kelimeler: Anadolu, Derekutuğun, Tarihöncesi Madencilik, Nabit Bakır, Madenci Çıraları.

Abstract: Archeological excavations conducted in 2009-2011 and 2015-2017 in the prehistoric mining galleries of Derekutuğun provided important information about the Anatolian mining in Prehistory. The native copper formed in the cracks and cavities of the Miocene sediments was mined by opening galleries in the 3 rd millennium BC. Among the small finds revealed in the galleries, the kindlings are of much importance. They were used to illuminate the mining galleries and cavities where copper was taken from. The kindlings that were made from the local pine trees of Anatolia constitute the most important material group of its kind in the Near East.

Keywords: Anatolia, Derekutuğun, Prehistoric Mining, Native Copper, Kindlings. 


\section{Giriş}

Birinci yazar 2003-2009 yılları arasında, madencilik tarihi konusunda Anadolu'nun tüm bölgelerini kapsayan araştırmalar gerçekleştirmiştir. Bu araştırmalar çerçevesinde bilinen maden yatakları ziyaret edilerek, buralarda eski işletme izleri olup olmadığı araștırılmış, örnekler alınarak analizleri yapılmıș ve böylece adı geçen maden yataklarının birnevi parmakizleri saptanmıştır. ${ }^{1} 2007$ yılında araştırmalar sürerken Çorum ili, Bayat ilçesi Derekutuğun köyü yakınlarında yer alan bakır yataklarında eski işletme izleri keşfedilmiş ve Kültür Varlıkları ve Müzeler Genel Müdürlüğü’nün izni ile 2009-2011 yıllarında Mazıönü Mevkii'nde yer alan tarihöncesi işletmelerde ve 2015-2017 y1llarında ise galerilerin $300 \mathrm{~m}$ güneyinde, Erikli Mevkii'nde yer alan „Madenci Yerleşimi'nde“ kazı çalışmaları gerçekleşmiştir $\left(\right.$ Resim 1). ${ }^{2}$

\section{Derekutuğun-Mazıönü Mevkii Tarihöncesi Bakır İşletmeleri}

Derekutuğun Köyü’nün doğusunda bulunan Mazıönü Mevkii’nde yürütülen ilk çalışmalar sırasında Miyosen yaşlı konglomeralardan oluşan ve batıya bakan dik yamaçlarda eski maden işletmelerinin kalıntıları saptanmıştır (Resim 2). Yukarıdan aşağıya doğru açılan kuyularla girilen ve genellikle cevherin uzandığı doğu-batı yönünde açılan galerilerin girişlerinin zamanla sel suları ve erozyon nedeniyle aşınıp yok olduğu anlaşılmaktadır. Bugün yamaçta görülen galeri ağızlarının son aşınma seviyesine ait kesitler olduğu ortaya çıkmıştır. Asıl girişleri doğal faaliyetlere bağlı olarak yok olan eski maden işletmelerinin birçoğu, yamaçta görülebilen kısımlarından girilmek suretiyle, uzun yıllar boyunca sürdürülen kaçak kazılarla meydana gelen tahribe maruz kalmıştır. Galerilerden bazılarının da zamanla yabani hayvan barınă̆ına dönüştüğü gözlenmiştir.

Mazıönü eski maden işletme alanları ve yakın çevresinde gerçekleştirilen yüzey araştırmalarında çok sayıda nabit bakır ve keramik parçası ile karşılaşılmıştır. Özellikle galerilerin erozyonla açılmış kesitlerinde görülen, yerlerinde korunmuş keramik parçaları alanın tarihöncesi dönemlerdeki kullanım yoğunluğunu ortaya koymaktaydı. Çevrede yürütülen çalışmalarda, Mazıönü'nün kuzeydoğusunda yer alan Karanlıkdere/Bakırdere ve Derekutuğun Köyü'nün batı sınırında bulunan Hıdırbağ mevkilerinde de eski maden işletme yerleri tespit edilmiştir. Özellikle Mazıönünde oluşan vadinin ve Karanlıkdere/Bakırdere vadilerinin son hallerini yan yana açılmış çok sayıda işletmenin zamanla sel suları ve erozyonla aşınması nedeniyle aldığı düşünülmektedir (Resim 3).

Söz konusu geniş alanda yürütülen çalışmaların ardından, eski maden işletme izlerinin yoğun olduğu ve nispeten daha iyi korunduğu Mazıönü Mevkii'nde 2009 yılında ilk kazılara başlanmıştır. 2010 ve 2011 yaz sezonunda devam eden çalışmalarda 1, 2, 5/5a ve 6 no.lu galerilerde, 2015-2016 sezonlarında ise 2 no.lu galerinin yanısıra 3, 4 ve 11 no.lu galerilerde kazı çalışmaları yürütülmüş̧ür (Resim 4). Şimdiye dek çalışılan galeri komplekslerinde çok sayıda çanak parçası ve toplam 8 adet iyi korunmuş, büyük boy çömlek ortaya çıkarılmıştır (Resim 5). Çanak çömlek buluntularının kuyu gibi açılmış dikey çukurlarda ve galerilerin taban seviyelerinde yoğunlaştığı göze çarpmaktadır. Özellikle 1 ve 2 no.lu galeri komplekslerinde yüzlerce çanak parçası ele geçmiştir. Buna karşın taş, boynuz ve ahşap madenci aletlerine az rastlanmaktadır. Özellikle çalışma boşluklarının ve galerilerin taban seviyelerinde yüzlerce madenci çırasının uçlarına rastlanmıştır.

\section{Maden Galerilerinde Ele Geçen Çanak Çömlekler}

Galerilerde ele geçen çanak çömlek parçalarının birbirine benzerliği dikkati çekmektedir. El yapımı keramik açık kahve ve kırmızımsı renkte olup, siyahımsı-gri özlüdür. Katkı malzemesi olarak

\footnotetext{
${ }^{1}$ Bu çalışmalar Maden Tetkik Arama Genel Müdürlüğü (MTA) ile ortak veya MTA’nın lojistik desteği ile yürütülmektedir.

2 2009-2011 ve 2015-2017 sezonu çalışmaları Çorum Müze Müdürlügü adına birinci yazarın bilimsel başkanlığında uluslararası katılımla gerçekleşti. Çalışmalar Deutsche Forschungsgemeinschaft (DFG)'ın maddi ve Bochum Alman Madencilik Müzesi'nin (DBM) kurumsal ve maddi desteği ile gerçekleşti. Detaylı bilgi için bkz. Yalçın ve İpek 2015.
} 
saman, mineral ya da hem saman hem mineral bir arada kullanılmıștır. Ele geçen parçalar arasında orta büyüklükteki çömlek ve güveç benzeri mutfak kapları çoğunluğu oluşturmaktadır. Birçoğunun üzeri kırmızı parlak boya astarlı olup, uzun süre nemli ortamda kalmaktan ve sel sularıla galeriler içinde oraya buraya taşınmaktan yüzeyleri yıpranmış ve aşınmıştır. Profil veren bir çok parçanın omuzlarında ya da omuzla karın arasında kalan bölümlerinde karşılıklı memecikler bulunmaktadır. Bunlardan bazıları süs öğesi işlevini üstlenirken bazıları da çömleği taşımaya veya iple bir yere asmaya yönelik yardımcı öge olarak kullanılmış olmalıdır. Çömleklerin çoğu boyunsuz ya da kısa boyunlu olup küresel gövdelidir. Dışa kıvrılan dudaklar bulunmakla birlikte, ağız kısımları çoğunlukla düz dudaklıdır. Orta büyüklükteki çömlekler arasında boyunsuz, içe doğru daralan ağız ve dışa kıvrılan dudaklı kaplar da yer almaktadır. Ayrıca omuzları sokma bezekli ve siyah parlak açkılı parçalar da göze çarpmaktadır (Resim $6)$.

Maden galerilerinde ele geçen çanak çömlekler biçimleri itibari ile Orta Anadolu'nun Geç Kalkolitik ve İlk Tunç Çağı I-II-III yerleşmelerinden Büyük Güllücek, Alacahöyük, Alişar, Ahlatlıbel ve özellikle Resuloğlu (KST 31/2) kap formlarını, repertuvarına Güneydoğu Avrupa ilişkilerinin de yansıdığı Doğu Karadeniz Bölgesi İkiztepe'nin bazı formlarını ve Doğu Anadolu Erken Karaz ve Geç Uruk çanak çömlek gruplarının Tepecik, Pulur-Sakyol XI-X ve Arslantepe VIA eş zamanlı çanak çömleğinin bilinen bazı öğelerini, dolayısıyla maden alışverişine dayalı kültür ilişkilerini yansitmaktadir.

\section{Derekutuğun Bakırı}

Derekutuğun cevher yatakları nabit bakır içermektedir (Resim 7). Miosen yaşlı konglomeralar içinde damarlar halinde nabit bakır oluşmuştur. Kimyasal analizi yapılan örnekler \% 99 un üstünde saf bakırdan oluşmaktadır. Ana metal olan bakır eser miktarda demir, çinko ve arsenik içermektedir. Ayrıca 140-350 ppm oranında gümüş de mevcuttur.

Kimyasal analizlerin yanısıra bakırın kurşun izozop analizleri de yapılmıştır. Bilindiği gibi kurşun izotop analizi arkeolojik metal buluntuların geliş kaynağı tesbitinde yaygın olarak kullanılan bir yöntemdir. Cevher yatakları kurşun izotop dağılımına göre karekterize edilmekte ve böylece bir nevi parmak izi alınmaktadır. Maden yatakları arkeolojik buluntuların analizleri ile karşılaştırılarak olabilecek ilişkileri tartışılmaktadır. Söz konusu analiz ve araştırmalar Derekutuğun bakırının nereye gönderildiği konusunda temel oluşturmaktadır.

Nabit bakır Miosen konglomerasının içinde ya da çatlaklarıyla yarıklarında bulunur. Sedimanların oluşumu nummulitler (kabuklu su yumuşakçaları) yoluyla Miosen'e tarihlenmektedir. Söz konusu sedimanlar olasılıkla şiddetli havza hareketleri sırasında oluşmuştur. Bölgenin diğer sedimanları tipik kızıl görünümleriyle belirlenir; bu sedimanlar kızıl renkte kum, kil, karbonat ve yer yer jips ile tuz birikimlerinden meydana gelmektedir. Bayat'ın bazı yörelerinin yanısıra Osmancık ve Dodurga'da kömür yatakları bulunmaktadır. Söz konusu olgu yüksek derecede tuzlanma gösteren denizel bir ortama işaret etmektedir. Taban suyunda bulunan sülfat ve klorla ilintili bu yüksek tuzlanmadan dolayı bakırın oluştuğu varsayılmakta, bakırın suda çözülüp yoğunlaştığı ve sonradan indirgenmiş ortamlarda, konglomeranın içinde nabit halde toplandığı anlaşılmaktadır. İndirgenme sedimandaki bitkisel oran nedeniyle de ivme kazanmış olmalıdır. Buna göre Derekutuğun bakır yataklarını „red-bed“ tipi olarak tanımlamak da mümkündür. Yan kayaçlardaki yüksek sayılabilecek vanadium değerleri ile bakırın içerdiği yüksek gümüş oranı bu varsayımı desteklemektedir. Delice-Yerköy yöresindeki aynı tipteki bakır yataklarında da yüksek gümüş ve vanadium değerleri saptanmıştır (Aral 1990: 67-71).

Elimizdeki bilimsel araştırma sonuçlarından yola çıkıldığında, Derekutuğun tarihöncesi bakır yataklarından olasılıkla İlk Tunç Çağı öncesinden beri yararlanıldığı ve söz konusu bakır yataklarının Anadolu'nun önemli tarihöncesi bakır kaynakları arasında yer aldığı anlaşılmaktadır. Derekutuğun'da son derece saf olan nabit bakırın bulunması ve izabe yoluyla elde edilen bakırın aynı saflığa erişemeyeceği gerçeği, bu işletmenin bölgede tartış1lamaz üstünlüğünü açıklayabilecek niteliktedir. 


\section{Madenci Çıraları}

Derekutuğun mazıönü tarihöncesi bakır işletmelerinde ele geçen küçük buluntular arasında en büyük grubu madenci çıraları oluşturmaktadır. Tüm galerilerin tasfiye düzlemlerinde 1650 çıra parçası ve yüzlerce kömürleşmiş çıra uçları ele geçmiştir. Özellikle 5/5a galeri kompleksinde killi bir tabakanın altında, ince kumlu dolguların içinde nemli ortamda iyi saklanmış çıralar toplu halde bulunmuştur (Resim 8). Yassı kibrit çöpünü andıran çıraların boyları 4-18 cm arasında, kalınlıkları ise $0,1-1,3 \mathrm{~cm}$ arasında değişmektedir (Resim 9). Çıraların yarıdan fazlası (\% 55) 6 cm'den daha kısa, ancak \% 10 kadarı ise $10 \mathrm{~cm}$ 'in üzerindedir. Genel olarak bir uç yanmıştır. Bazı çıraların ise her iki ucunun da yandığı anlaşılmaktadır. Asıl uzunlukları 30-50 cm arasında değişen çıraların bir kısmı madene giden galerilerin duvarlarına sabitlenirken diğer bir kısmı da elde taşınıyordu. Elde taşınan çıralar yanıp kısaldıkça galerilere atılıyordu. Bu yüzden kullanılmış çıralar genel olarak galeri ve maden alma boşluklarının taban seviyelerinde ele geçmiştir.

Çoğunlukla çam gibi bol reçineli ağaçlardan elde edilen çıralar geçmişte hem günlük yaşamda hem de madenciler tarafindan ateş tutuşturmak ve aydınlanmak amacıyla kullanılmaktaydı. Derekutuğun maden galerinde ele geçen çıralar da bölgenin yerli çam ağaçlarından (pinus sp.) elde edilmiştir. Benzer madenci çıraları Avrupa 'nın çeşitli bölgelerinde bulunan Tunç ve Demir Çağları'ndan kalma maden ocaklarından bilinmektedir (Thomas 2009). Örnek olarak Auvusturya'da Hallstatt ve Dürrnberg tuz işletmeleri ve Bischofshofen yakınlarında Mitterberg tarihöncesi bakır işletmeleri (Dobiat ve Stöllner 2000; Kern vd. 2008) verilebilir. Buralarda kullanılan çıralar yine bölgenin yerli çam ve köknar ağaçlarından elde edilmiş̧ir (Kern vd. 2008). Yanı sıra, İrlanda'da Tunç Çağları'na tarihlenen Mt. Gabriel bakır işletmelerinde de bölgenin yerli çamlarından yapılmış madenci çıralarından bahsedilmektedir (Kern vd. 2008: 57; O’Brien 1994: 158-161).

Kurak iklimin hakim olduğu Önasya' da ise benzer buluntulara daha nadir rastlanır. Literatürde Umman, Timna ve Anadolu eski maden işletmelerinde madenci çıralarından bahsedilmemektedir. Ürdün Fenan Bölgesi‘nde bulunan eski bakır işletmelerinde, 41 no.lu kuyuda ele geçen az sayıdaki çıra ise istisna bir buluntu sayılır (Hauptmann 2000). Bu kapsamda Derekutuğun Tarihöncesi Bakır İşletmeleri'nde ele geçen madenci çıraları türlerinin Önasya'daki en yoğun buluntusunu oluşturur.

Çıraların yanısıra 5a no.lu işletme kuyusunda, yine nemli ortamda korunagelmiş beş adet ahşap madenci aletli ele geçmiştir. Ahşap buluntulardan üç tanesinin meşe (quercus sp.), bir tanesinin dişbudak (faxinus sp.) ve diğerinin ise findık (colylus $s p$.) ağacından olduğu anlaşılmaktadır. Sayılan ağaç türleri özellikle sağlam ve dayanıklı türlerdir. ${ }^{3}$ Meşe, dişbudak ve findıktan oluşan üç ahşap buluntu manila benzeri aletler olup maden kazmak için kullanılmış olabilir. Meşeden yapılmış diğer iki buluntu ise kürek olarak kullanılmıştır (Resim 10).

Çıralar ve diğer ahşap buluntular aynı zamanda galerilerin tarihlendirilmesi için ideal buluntulardır. Yapılan 50 adet Radyokarbon analizi ${ }^{4}$ Mazıönü'nde araştırılan bakır işletmeleri için MÖ 2900-2650 tarihlerini öngörmektedir. Galerilerde ele geçen keramik buluntular da bu tarihi destekler niteliktedir.

\section{Sonuc}

Madenler Anadolu tarihinde daima önemli bir rol almıştır (Yalçın 2000; 2003; 2008; 2016). Buna rağmen konuyla ilgili sistematik araştırma yetersiz kalmaktadır. Bu kapsamda Niğde Kestel'de kalay madenciliği konusunda gerçekleşen çalışmalar (Yener vd. 1989) ve Tokat Kozlu'da yapılan küçük bir sondaj (Kaptan 1986) tekil örnekleri oluşturur. Buna son y1llarda Kayseri'de kalay yataklarında yürütülen çalışmalar da eklenebilir (Yalçın \& Özbal 2009; Yener vd. 2015). Derkutuğun'da 2009-2011 ve 2015-2017 yıllarında gerçekleşen çalışmalar bu kapsamda önem taşır ve Anadolu Kültür Tarihi‘ne, özellikle madencilik konusunda yeni bilgiler katmaktadır.

\footnotetext{
${ }^{3}$ Çıralar dahil ahşap buluntuların analizleri İsviçre'de, Langenau Labor für Quartäre Hölzer tarafindan yapılmıştır.

${ }^{4}$ Ahşap buluntuların Radyokarbon analizleri ETH Zürih Üniversitesi laboratuvarlarında yapılmıştır.
} 
Şimdiye dek yapılan gözlemlerden yola çıkıldığında Derekuğun'da gerçekleştirilmiş olan tarihöncesi maden işletmeleri aşağıdaki biçimde kurgulanabilinir: Bakır içeren çatlak, yarık ve damarları izleyen tarihöncesi madencileri Maziönü’ndeki tepelerde dikey kuyular açmış, bu kuyulardan ayrılan doğu-batı doğrultusunda ilerleyen galeriler oluşturarak maden çıkarmışlardır. Şimdiye dek araştırılan galerilerde en az beş ayrı kademede maden çıkarıldığı anlaşılmaktadır. Buna göre üstteki galeriler daha eski, altta kalan kademeler ise daha sonraki evreleri temsil etmektedir.

Madenci aletleri, aydınlanma çıraları ve galeri duvarlarındaki maden çıkarma izleri söz konusu dönemde madenciliğin eriştiği teknik düzeyi yansıtacak niteliktedir. Ayrıca aydınlanma çıraları Önasya'da İlk Tunç Çağı madenciliği kapsamında gün ışığına çıkarılan en zengin buluntu topluluğunu oluşturur.

Derekutuğun'da nabit bakır çıkarılmıştır. Söz konusu maden galerilerinden tonlarca nabit bakırın elde edildiği ve bu bakırın üstün kalitesi göz önünde bulundurulduğunda Derekutuğun'un geçmiş dönemlerde önemli bir bakır merkezi olduğu, bu önemli konumun yalnızca Anadolu ile sınırlı kalmayıp, komşu bölgeleri de kapsadığı varsayılabilir. Kaliteli bir hammade olan Derekutuğun bakırının yüksek derecedeki saflı̆̆ı nedeniyle zamanının aranılan bir hammaddesi olduğu düşünülmektedir. Kızılırmak'a yakın konumu ve ayrıca tarihöncesi ve antik yol güzergahları üzerinde oluşu dönemin önemli merkezleri ile bağlantısını kaçınılmaz kılmaktadır (Resim 11: Harita). İz element ve kurşun izotop analizleri yardımıyla Derekutuğun bakırının jeokimyasal özellikleri saptanmış, yani parmak izi çıkarılmıştır. Bu yolla Derekutuğun bakırları kaynak tartışmaları açısından da önemli bir veri tabanı oluşturmaktadır. Alacahöyük İlk Tunç Çağı bakır buluntularından alınan örneklerle yapılan ilk karşılaştırmalardan Derekutuğun madeninin Alacahöyük'te kullanılan bakırın geldiği kaynak olabileceği anlaşılmaktadır. ${ }^{5}$ Nabit bakırın yüzeyden kolayca toplanabilmesi nedeniyle Derekutuğun Anadolu'da Neolitik ve Erken Kalkolitik Çağlar'da kullanılan nabit bakır için de olası bir kaynak olarak düşünülebilir. Günümüzde dahi yağmurlu mevsimlerin sonunda Derekutuğun'deki dere yataklarında bakır parçaları toplanabilmektedir.

2015-2017 y1llarında galerilerin 300 m güneyinde yer alan madenci yerleşiminde yapılan kazı çalışmaları madenciliğin organizasyonu, madencilerin yaşamları ve ticari ilişkiler hakkında önemli bilgiler sunmuştur. Çalışmalar ve alınan sonuçlar değerlendirme aşamasında olup yayına hazırlanmaktadır. Bu kısa makale ile önemli bir malzeme grubu özetle tanıtılırken, Derekutuğun'un Anadolu Arkeoljisi'ndeki önemine de işaret etmek istenmiştir. Zira Derekutuğun'un Anadolu Kültür Tarihi ve özellikle madencilik tarihi açısından önem taşıdığı daha şimdiden anlaşılmaktadır.

\footnotetext{
${ }^{5}$ Derekutuğun bakırının ticareti ve İTÇ eliter merkezleriyle olan ilişsisi yayına hazırlanan Derekutuğun monografisinde detaylı olarak ele alınacaktır.
} 


\section{Resimler $^{6}$}

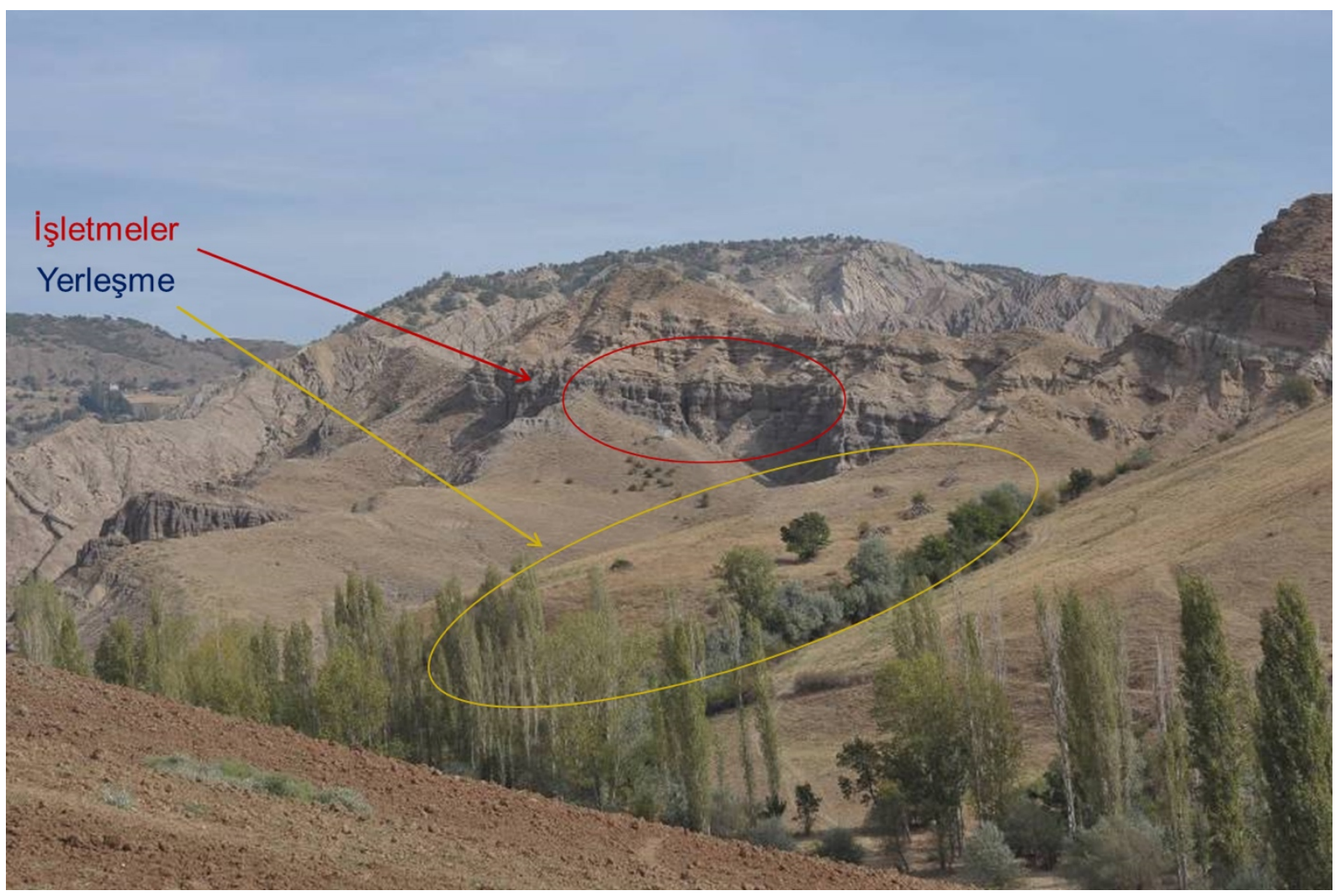

Resim 1: Derekutuğun Mazıönü Mevkii Tarihöncesi Maden İsletmeleri ve Erikli Madenci Yerleşmesi.

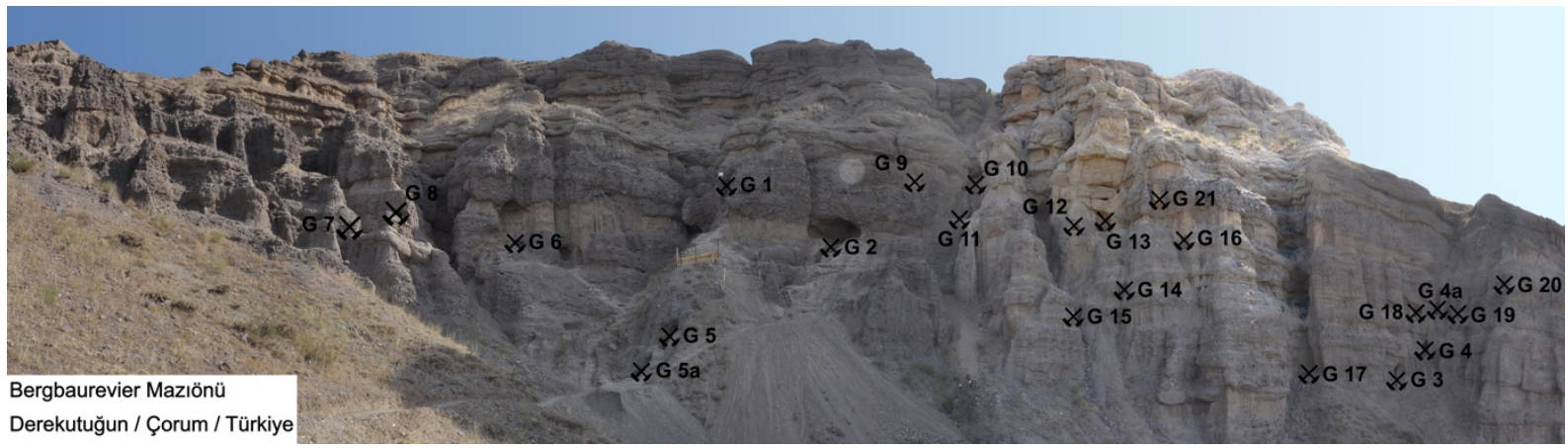

Resim 2: Mazıönü Mevkii eski maden işletmelerinin bulunduğu Miyosen yaşlı konglomeralardan oluşan sarp yamaç.

\footnotetext{
${ }^{6}$ Resimler Derekutuğun arşivinden alınmıştır.
} 


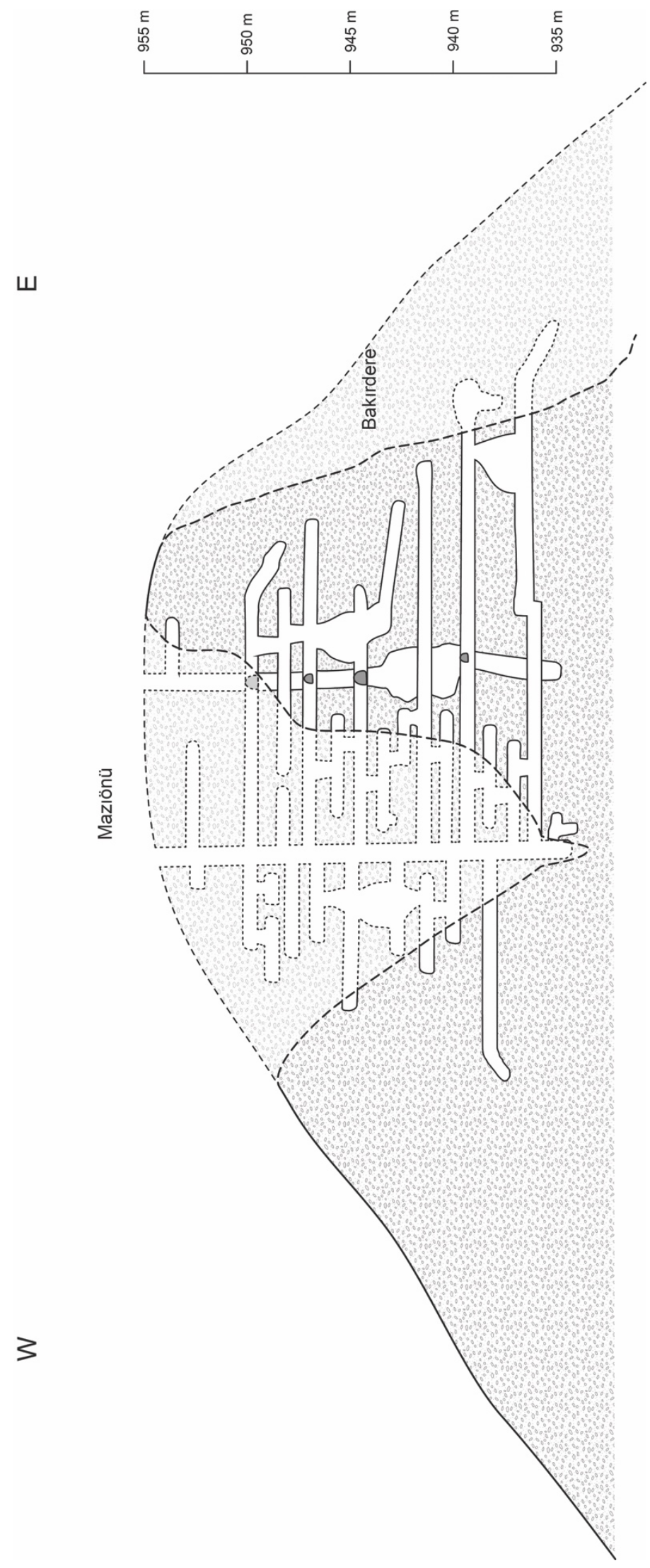

Resim 3: Mazıönü Tarihöncesi İsletmeleri ve erozyon nedeniyle bugünkü morfolojisini gösteren model. 


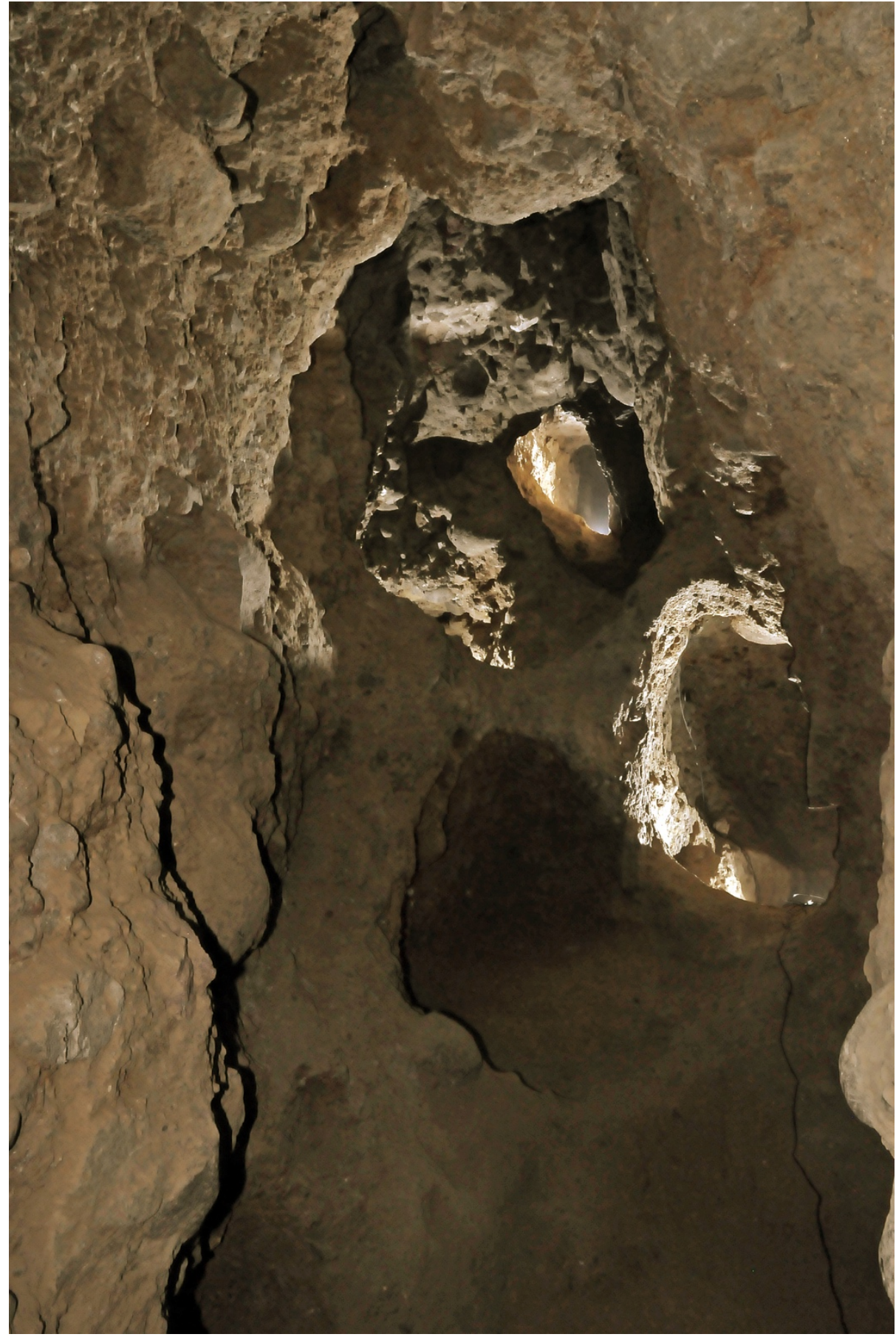

Resim 4: Mazıönü, 1. No.lu galeriden görüntü. 


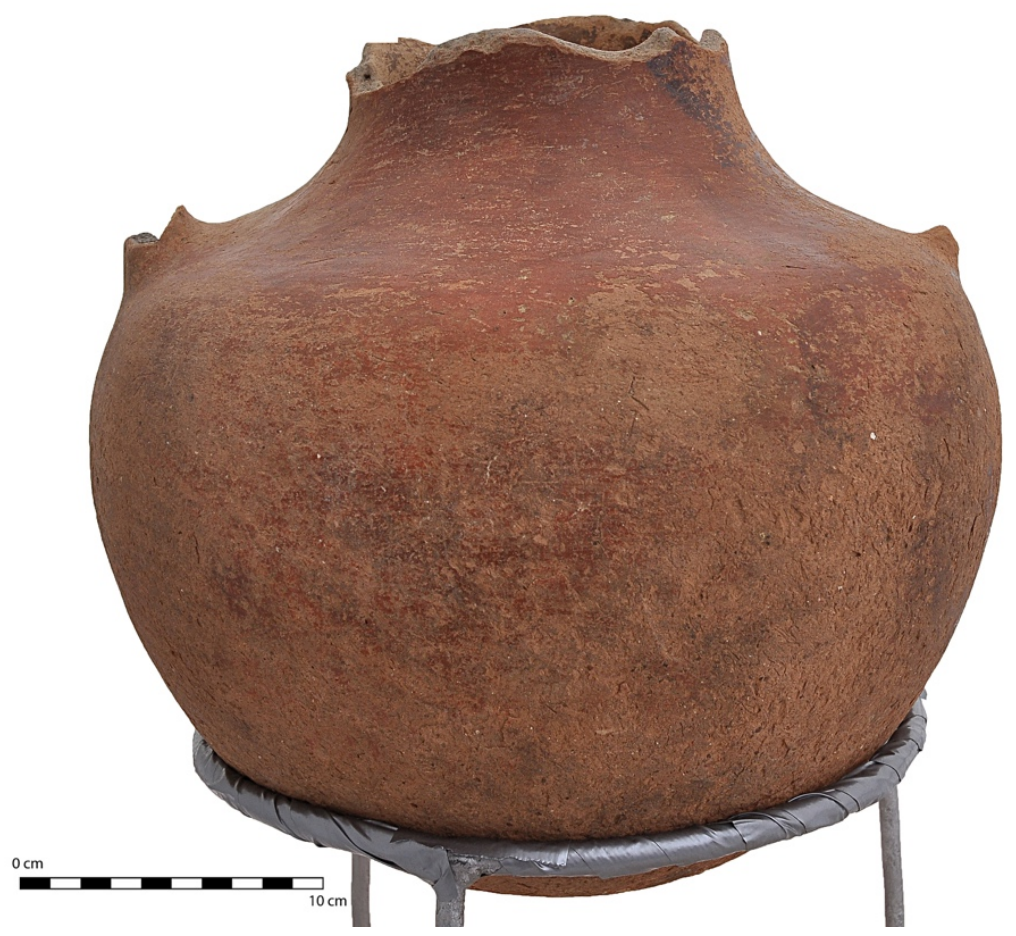

Resim 5: Maden galerilerinde gün ışı̆̆ına çıkan çömleklere örnek.

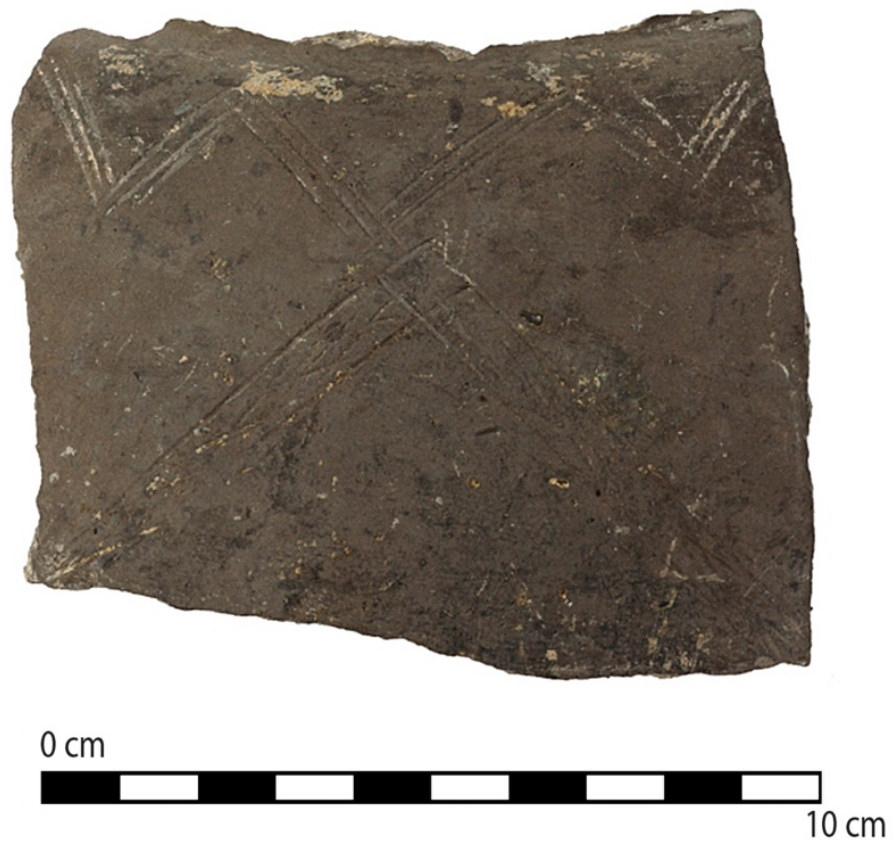

Resim 6: Galerilerde ele geçen bezemeli çanak parçalarına örnek. 

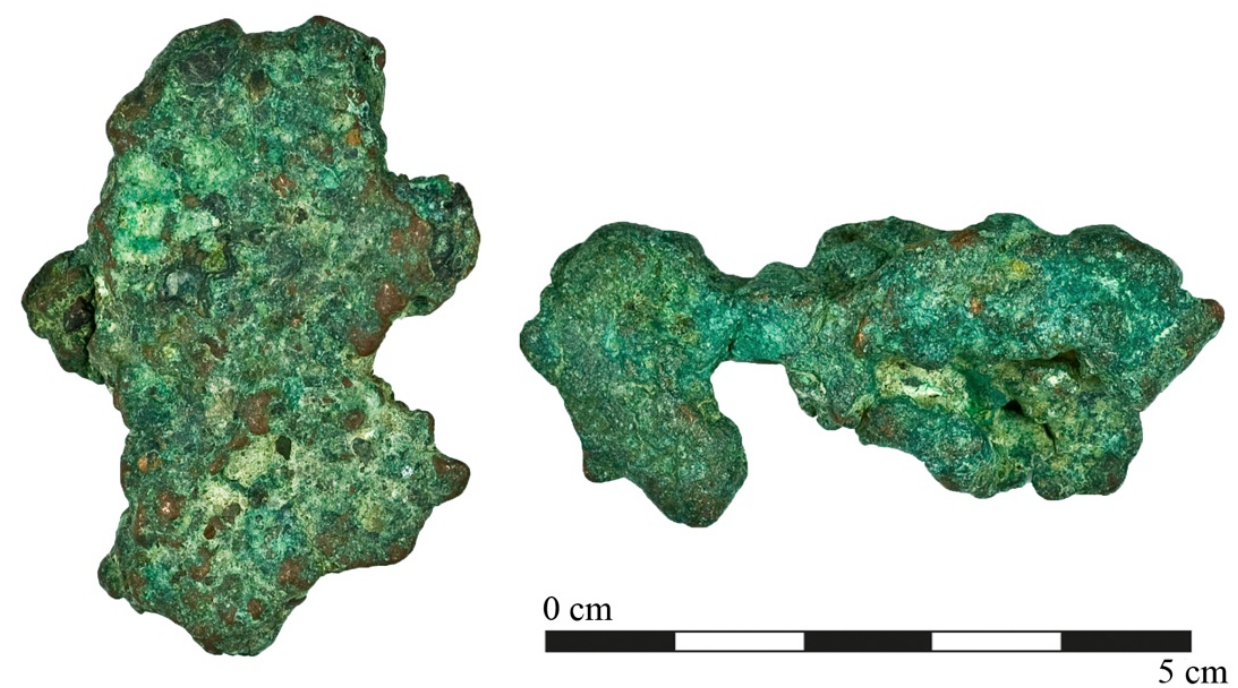

Resim 7: Galerilerde ele geçen nabit bakır yumrular.

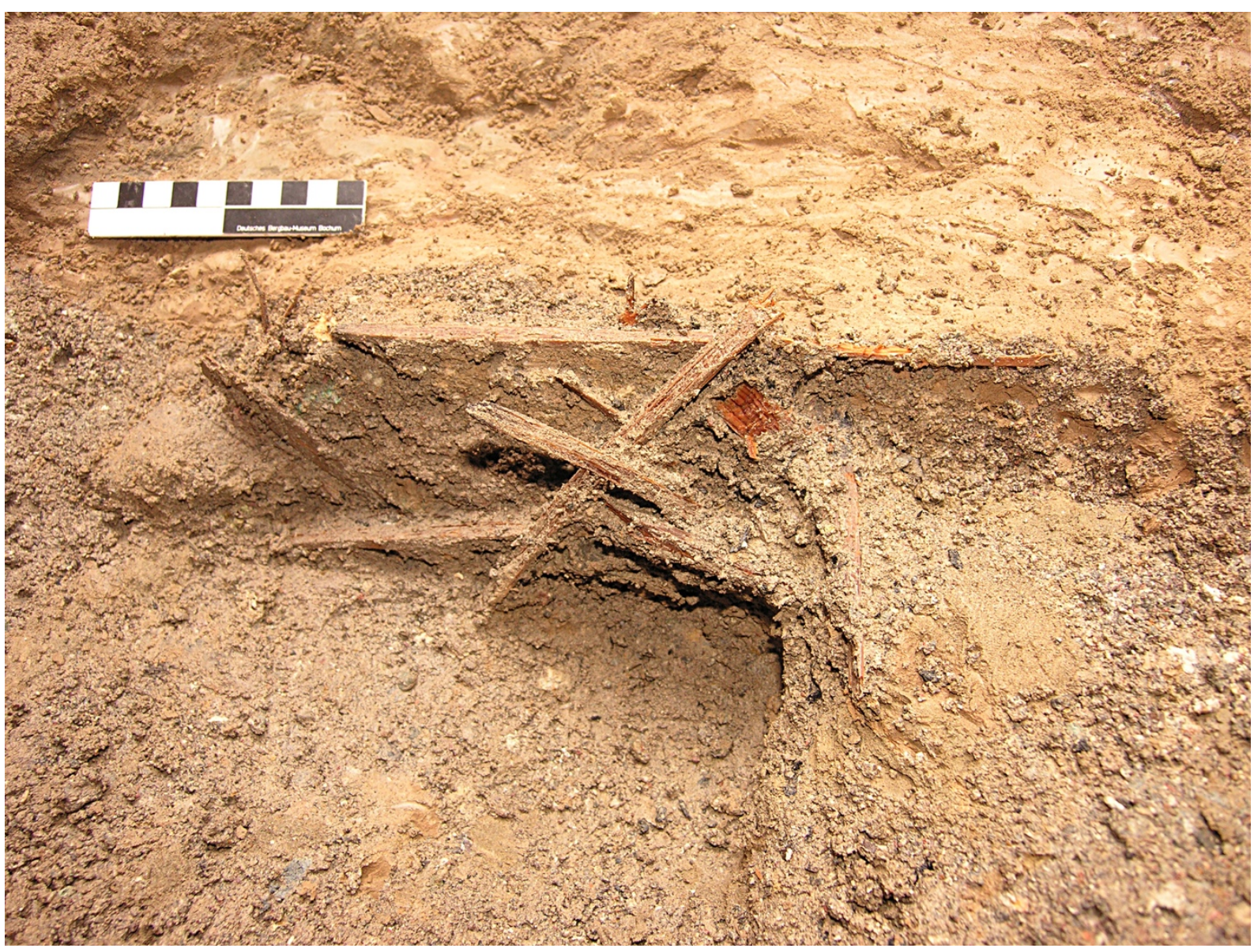

Resim 8: 5 a no.lu galeride gün ışı̆̆ına çıkan madenci çıra topluluğu. 


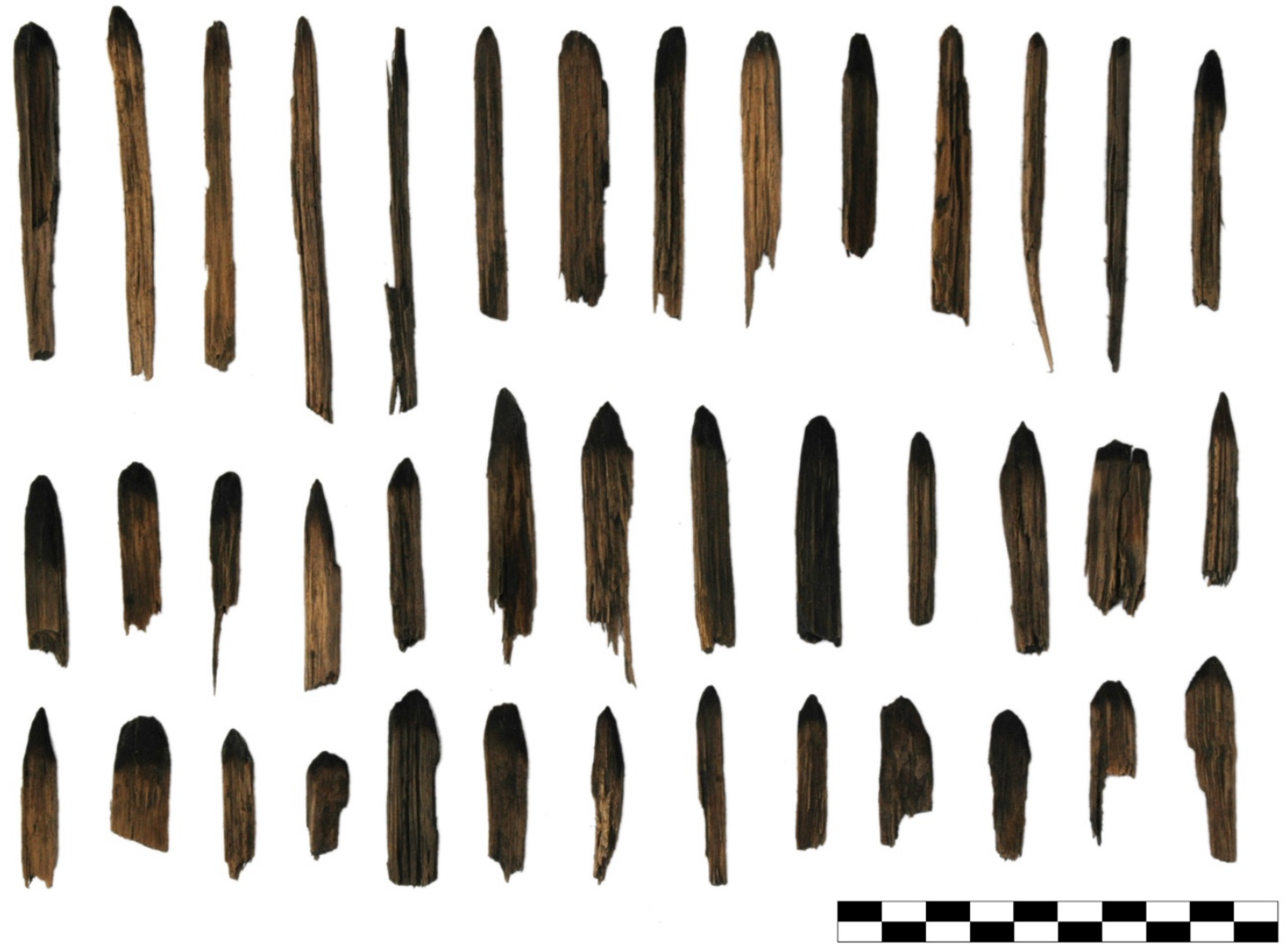

Resim 9: Madenci çıralarından bazı örnekler.
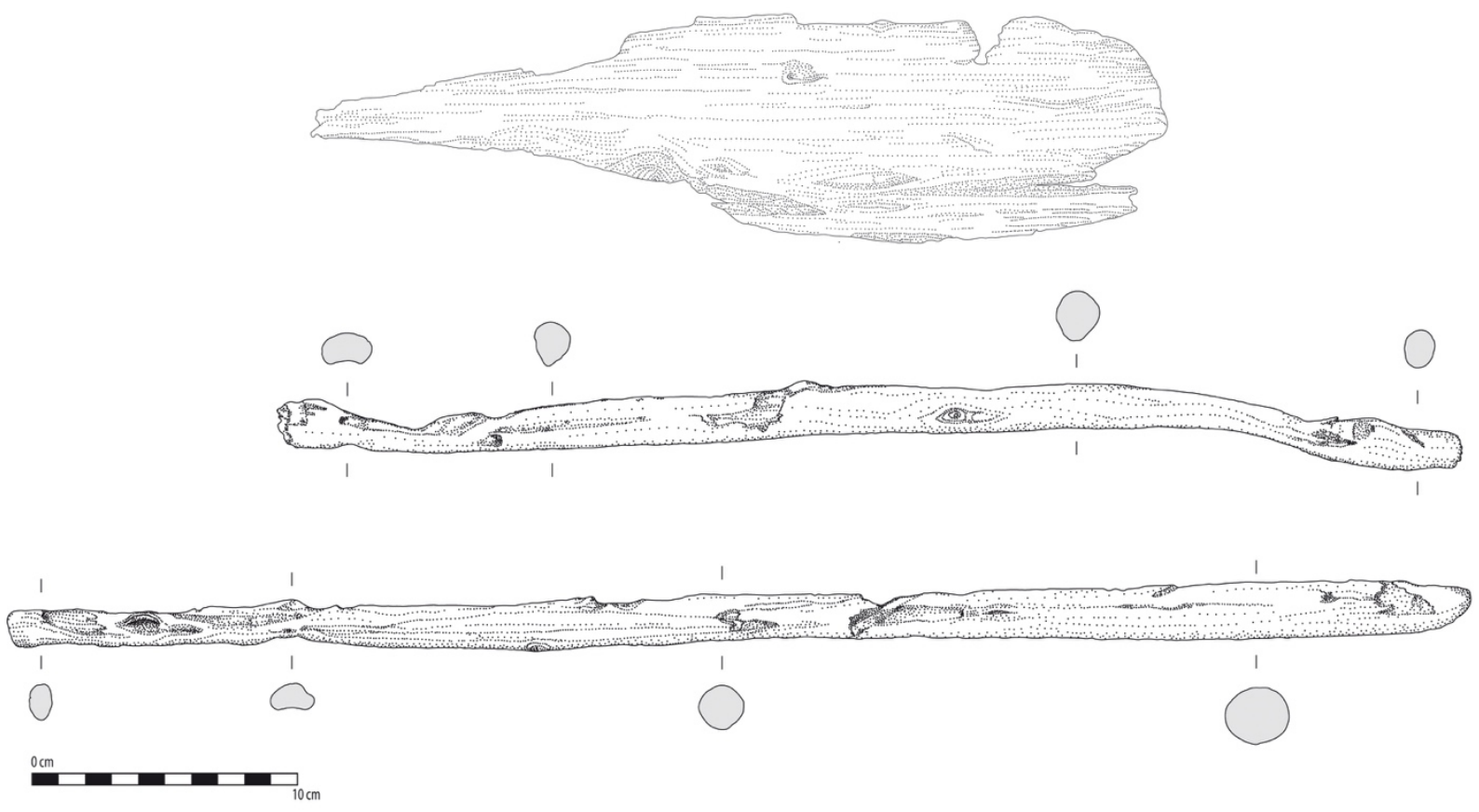

Resim 10: Ahşap aletlere örnek kürek ve manivela. 


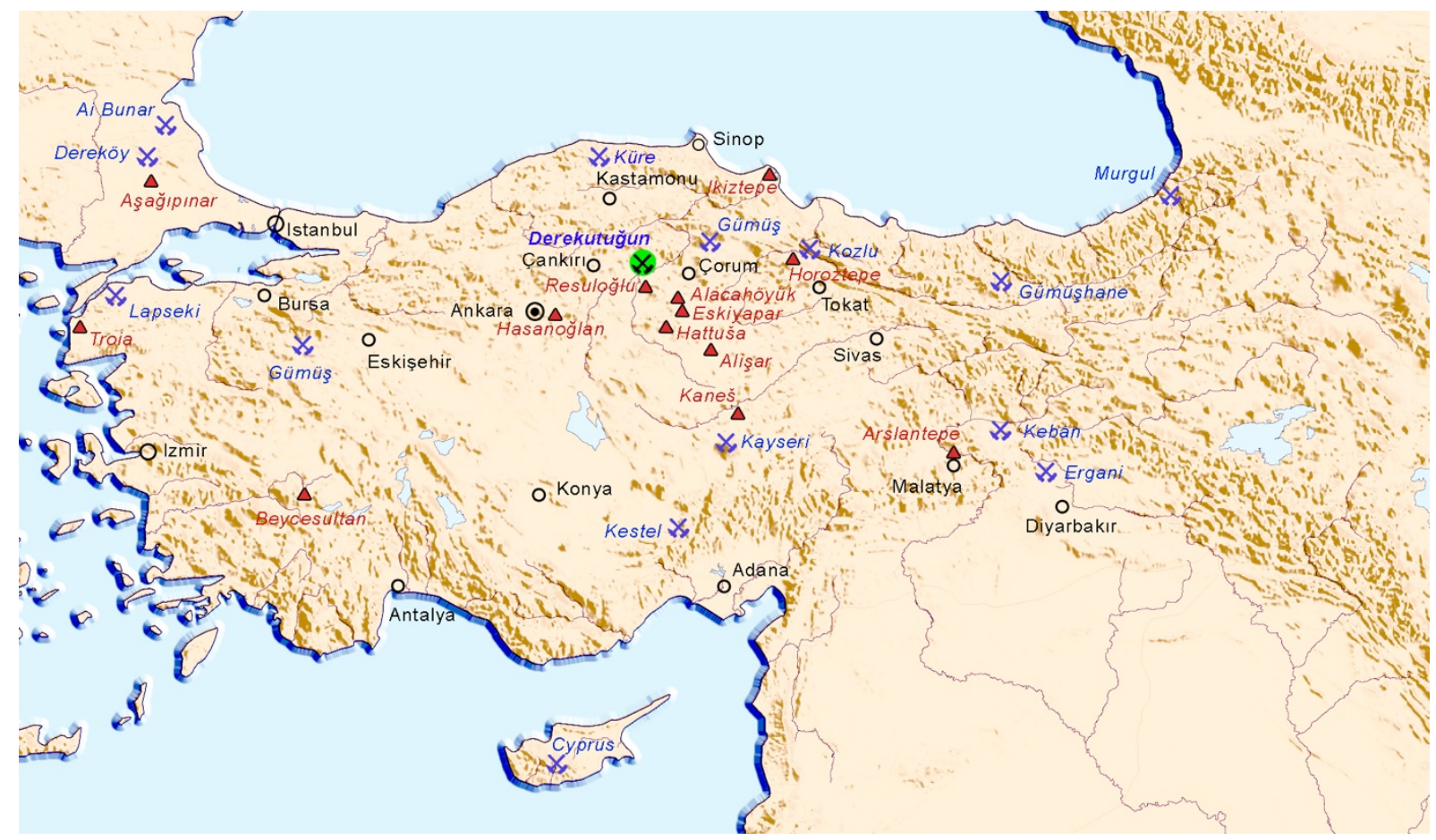

Resim 11: Anadolu haritası: Derekutuğun ve bazı önemli Tarihöncesi merkezler. 


\section{Kaynakça}

Aral, H. (1990). „Red Bed“ Tipi Bakır Yatakları ve Türkiye’den Örnekler. Madencilik XXX/2, 17-26.

Dobiat, C.-Stöllner, Th. (2000). Siedlungs- und Wirtschaftsgeschichte des Dürrnberges bei Hallein. Vorbericht zu den Gelände- und Laborforschungen des Ausgrabungsjahres 1998/1999. Archäologisches Korrespondenzblatt 37, 65-84.

Kaptan, E. (1986). Ancient Mining in the Tokat Province, Anatolia: New Finds. Anatolica 13, 19-36.

Kern, A.-Kowarik, K.- Rausch, A. W. ve Reschreiter, H. (2008). Salz-Reich. 7000 Jahre Hallstatt. Veröffentlichungen der Prähistorischen Abteilung 2. Wien: Naturhistorisches Museum.

O’Brien, W. (1994). Mount Gabriel. Bronze Age Mining in Ireland. Belfast: Galway University Press.

Thomas, P. (2009). Die Holzfunde aus dem prähistorischen Bergbau des Arthusstollens bei

Bischofshofen in Pongau. (Yayınlanmamış Yüksek Lisans Tezi) Marburg Üniversitesi. Marburg.

Yalçın, Ü. (2000). Anfänge der Metallverwendung in Anatolien. Ü. Yalçın (ed.) Anatolian Metal I (s. 17-30). Der Anschnitt, Beiheft 13, Bochum: Deutsches Bergbaumuseum-Bochum.

Yalçın, Ü. (2003). Metallurgie in Anatolien. Th. Stöllner, G. Körlin, G. Steffens ve J. Cierny (Eds.). Man and Mining. Studies in Honour of Gerd Weisgerber on Occasion of his 65th Birthday (s. 527536). Der Anschnitt, Beiheft 16, Bochum: Deutsches Bergbaumuseum-Bochum.

Yalçın, Ü. (2008). Ancient Metallurgy in Anatolia. Ü. Yalçın, H. Özbal ve A. G. Paşamehmetoğlu (eds.). Ancient Mining in Turkey and the Eastern Mediterranean (s. 15-42). Ankara: Atılım University.

Yalçın, Ü. (2016). The Beginnings of Metal Use in West Asia. Ancient West Asian Civiliazation. Springer Verlag. 115-132.

Yalçın, Ü.-İpek, Ö. (2015). Prähistorische Kupfergewinnung in Derekutuğun, Anatolien. Der Anschnitt, Beiheft 30. Bochum.

Yalçın, Ü.-Özbal, H. (2009). Ein neues Zinnvorkommen in Kayseri-Hisarcık, Zentralanatolien: Ein Vorbericht. Tüba-Ar 12, 117-122.

Yener, K. A.-Özbal, H.-Kaptan, E.-Pehlivan, N. ve Goodway, M. (1989). Kestel: An Early Bronze Age Source of Tin Ore in the Taurus Mountains, Turkey. Sciences 144, 200-203. 
Yener, K. A.-Kulakoğlu, F.-Yazgan, E.-Ryoichi, K.-Hayakawa, Y. S.-Lehner, J. W.-Dardeniz, G.Öztürk, G.-Johnson, M.-Kaptan, E. ve Hacar, A. (2015). New Tin Mines and Production Sites Near Kültepe in Turkey: a Third-Millennium BC Highland Production Model. Antiquity 89, 596-612. 